\title{
Variation of vegetative and floral traits in the alpine plant Solidago minuta: evidence for local optimum along an elevational gradient
}

\author{
Piotr Kiełtyk ${ }^{1}$ (1)
}

Received: 2 May 2017 / Accepted: 24 November 2017 / Published online: 30 November 2017

(c) The Author(s) 2017. This article is an open access publication

\begin{abstract}
Alpine plants growing along wide elevational gradients experience very different abiotic and biotic conditions across elevations. As a result of genetic differentiation and/or plastic response, conspecific plants growing in high elevations, as compared to low elevations, generally have shorter stems and lower number of flowers, but larger flower size. However, most often, detailed models of elevational variations were not examined. To reveal the pattern of elevational changes in a set of fitnessrelated morphological traits, tests of linear and unimodal models were performed based on measurements of 1047 Solidago minuta plants collected from 47 sites distributed along a 1000 m elevational gradient in the Tatra Mountains. Nearly all of the investigated floral traits, i.e. inflorescence and flower heads size, and number and size of individual flowers, expressed unimodal relationships with elevation having their maxima in the centre of the elevation range. This pattern suggests the existence of a local optimum with respect to sexual reproduction at the centre of the elevational range. Possible explanations of observed elevational variations are discussed in the context of pollinator selection and the 'resource-cost compromise' hypothesis. Best floral performance in the centre of the elevational range of $S$. minuta may also support the idea that the favourability of habitat conditions declines from the centre to the margin of the distribution, and species are expected to be more abundant, increase reproduction and perform better in the centre of the range.
\end{abstract}

Keywords Altitudinal gradient · 'Centre-periphery' hypothesis · Morphology $\cdot$ Phenotypic variation · Species range

\section{Introduction}

Plants growing along wide elevational gradients in mountains experience very different abiotic and biotic conditions, which change considerably over relatively small vertical distances. Environmental factors associated with the increase in elevation in mountains of temperate seasonal zones include reduction in mean temperature and $\mathrm{CO}_{2}$ partial pressure, decrease in the length of the growth period and prolonged duration of snow cover, reduction in soil microbial activity and resource competition among plants, decrease in nutrient availability, increase in light intensity and UV radiation, increase in precipitation and wind velocity (Billings 1974; Körner 2003, 2007). Elevation in mountains is a complex ecological factor comprised of many abiotic and

Piotr Kiełtyk

kieltyk@wp.pl

1 Faculty of Biology and Environmental Sciences, Cardinal Stefan Wyszyński University in Warsaw, Wóycickiego 1/3, 01-938 Warszawa, Poland biotic components which are vital for plant growth and cannot be easily separated. Therefore, the elevational gradient has been considered as the most important factor in studies on phenotypic variation of plant species in mountains (e.g. Stöcklin et al. 2009; Št'astná et al. 2012; Kim and Donohue 2013; Scheepens and Stöcklin 2013; Gugger et al. 2015; Hamann et al. 2016; Stöcklin and Armbruster 2016; Sakurai and Takahashi 2016; Takahashi and Matsuki 2016). Plants can respond to elevational changes based on their morphological and physiological plasticity and through local adaptations (Hirano et al. 2017). Alpine plant species, compared to lowland plants, have distinctly smaller overall size (e.g. Körner and Renhardt 1987; Blionis and Vokou 2002; Guo et al. 2010), allocate more biomass to underground organs (Körner and Renhardt 1987; Ma et al. 2010) and locate more of their aboveground biomass to flowers (Fabbro and Körner 2004). Morphological differences along elevational gradients are also visible at the intraspecific level in species distributed along wide elevational ranges. Plants growing in high elevation, as compared to low elevation, have shorter stems (Nishizawa et al. 2001; Alexander et al. 
2009; Takahashi and Yoshida 2009; Maad et al. 2013), lower numbers of flowers (Kelly 1998; Baret et al. 2004; Maad et al. 2013) and lower numbers of flower heads (Asteraceae family) (Kelly 1998; Alexander et al. 2009), but larger flower sizes (Kudo and Molau 1999; Malo and Baonza 2002; Herrera 2005; Maad et al. 2013). In addition, along with an increase in elevation, plants possess higher plasticity of flower longevity (Trunschke and Stöcklin 2017), increase clonality, tend to be older (Št'astná et al. 2012) and produce more flowering shoots (von Arx et al. 2006).

Although numerous studies have documented elevational variation in plant morphological traits, the nature of the relationship between traits and elevation has rarely been examined. Often, only the existence of linear relationships (i.e. straight line) between traits and elevation is tested by means of simple linear regression (e.g. Kelly 1998; von Arx et al. 2006; Alexander et al. 2009; Wirth et al. 2010; MontesinosNavarro et al. 2011). Applying a simple linear regression model assumes the existence of a monotonic (only decreasing or increasing) relationship between plant traits and elevation, most often as a result of plant responses due to plasticity and/or adaptation to changes in climatic conditions along the elevation (e.g. von Arx et al. 2006; Alexander et al. 2009; Wirth et al. 2010; Montesinos-Navarro et al. 2011). However, plant species with wide elevational ranges are expected to be exposed to different selective pressures at low and high elevations (Frei et al. 2014a), and this may result in non-linear responses in some traits along the elevational gradient. For example, Malo and Baonza (2002) in their study on plant-pollinator interactions along an elevational gradient found that the Cytisus scoparius flower size in the mountains of Central Spain had a unimodal relationship with elevation and the maximum size occurred at the intermediate elevation. This curvilinear, unimodal relationship may be explained as a result of the trade-off between pollinator selection for larger flowers in higher elevations (e.g. Totland 2001, 2004; Malo and Baonza 2002; Maad et al. 2013) and the selection suggested by the 'resourcecost compromise' hypothesis, according to which smaller flowers are advantageous in unfavourable environmental conditions due to the lower cost of their development and maintenance (Herrera 2005). Hence, the abiotic selection for smaller flowers at higher elevations can prevent a response in flower size to selection from pollinators (Zhao and Wang 2015). The existence of a unimodal relationship between morphological traits and the elevational gradient may also be predicted based on the idea that populations from the centre of the species range perform better than marginal populations. According to this 'centre-periphery' hypothesis, the populations from the centre of the range should be more abundant and perform better than those from the periphery because habitat suitability decreases from the range centre to the periphery (Hengeveld and Haeck 1982; Brown 1984).
Similarly, the 'abundant centre model' (ACM, Vaupel and Matthies 2012), or 'abundant centre distribution' (ACD, Herrera and Bazaga 2008), predicts that the favourability of habitat conditions declines from the centre to the margin of the distribution and that species are expected to be more abundant, increase reproduction and perform better in the centre of their range (Jump and Woodward 2003; Vaupel and Matthies 2012).

To understand the role of environmentally induced phenotypic plasticity and genetic effects in plant intraspecific variation along elevational gradients, studies based on the results of the transplantation of plants (or growing them from seed), originating from different elevations, to the common garden (e.g. Neuffer and Bartelheim 1989; Hirano et al. 2017) or reciprocal transplantation to plots located at different elevations (e.g. Gonzalo-Turpin and Hazard 2009; Hautier et al. 2009; Scheepens et al. 2010; Hamann et al. 2016) are essential. However, knowledge on variations in morphological traits and plant performance in natural populations along elevational gradients is also important to understand the role of natural selection in plant adaptation to alpine environments and plant phenotypic responses to such conditions (Clausen et al. 1948; Gonzalo-Turpin and Hazard 2009; Bastida et al. 2015). Moreover, it has been emphasized that, in the context of present and predicted future climate changes, knowledge of plant performance along elevational gradients may contribute to an enhanced prediction of plant responses under an altered climate (Theurillat and Guisan 2001; Felde et al. 2012; Frei et al. 2014b).

The aim of this paper is to examine models of elevational changes in a set of fitness-related morphological traits of the alpine plant, Solidago minuta L., along a 1000 m elevational gradient in the Tatra Mountains in the Western Carpathians. Specifically, the paper addresses the following question: do the morphological traits of $S$. minuta change monotonically, i.e. only increasing or decreasing their values with an increase in elevation as a response to environmental gradients, or are there non-linear relationships between fitness-related traits and elevation with maxima at intermediate elevations suggesting the existence of a local optimum along an elevational gradient?

\section{Materials and methods}

\section{Species and study area}

Alpine goldenrod (S. minuta L., syn. Solidago virgaurea ssp. minuta, Asteraceae) is a perennial, yellow-flowered alpine plant growing in European high-mountain chains extending from the Sierra Nevada through the Pyrenees and Alps to the Carpathians and Dinaric Alps (Wagenitz 1979; Slavík 2004). Flowers gathered in flower heads are 
insect-pollinated with outer female ligulate flowers and inner hermaphrodite tubular flowers. From the closely related Solidago virgaurea $\mathrm{L}$. that is widespread in the lowlands throughout Europe, alpine $S$. minuta differs in many of its morphological traits, especially in those related to flower heads and flowers. S. minuta, as compared to $S$. virgaurea, has a smaller stature with a shorter stem, larger flower heads and considerably more tubular and ligulate flowers per head (Kiełtyk and Mirek 2014).

The investigated elevational gradient was located in the Polish area of the Tatra Mountains, (Fig. 1, the highest peak in the Slovak part is $2655 \mathrm{~m}$ a.s.l. and in the Polish part, $2499 \mathrm{~m}$ a.s.1.) which is the highest chain in the arc of the Carpathians. The mean annual temperature decreases from ca. $+6{ }^{\circ} \mathrm{C}$ at the foothills of the Polish Tatras (ca. $900-1000 \mathrm{~m}$ a.s.1.) to $-2{ }^{\circ} \mathrm{C}$ at $2200 \mathrm{~m}$ a.s.1., and $-4{ }^{\circ} \mathrm{C}$ at the highest peaks. The mean annual sum of precipitation measured at the foothills at the weather station in Zakopane town at an elevation of $844 \mathrm{~m}$ a.s.l. is $1138 \mathrm{~mm}$, and, at the weather station on the Kasprowy Wierch peak at an elevation of $1991 \mathrm{~m}$ a.s.l., it amounts to 1876 mm (Hess 1996). In the Polish Tatra Mountains, $S$. minuta has been found to grow at elevations from ca. 1100 to $2300 \mathrm{~m}$ a.s.l.; however, the main centre of the species range is at elevations from 1500 to $1900 \mathrm{~m}$ a.s.l. (Fig. 2), which in the Polish Tatra Mountains corresponds to the subalpine belt and the lowest part of the alpine belt. The phytosociological optimum of this species in the study area is in subalpine tall herb and tall grass vegetation (the Mulgedio-Aconitetea class) and grazed seminatural vegetation (Kiełtyk and Mirek 2017).

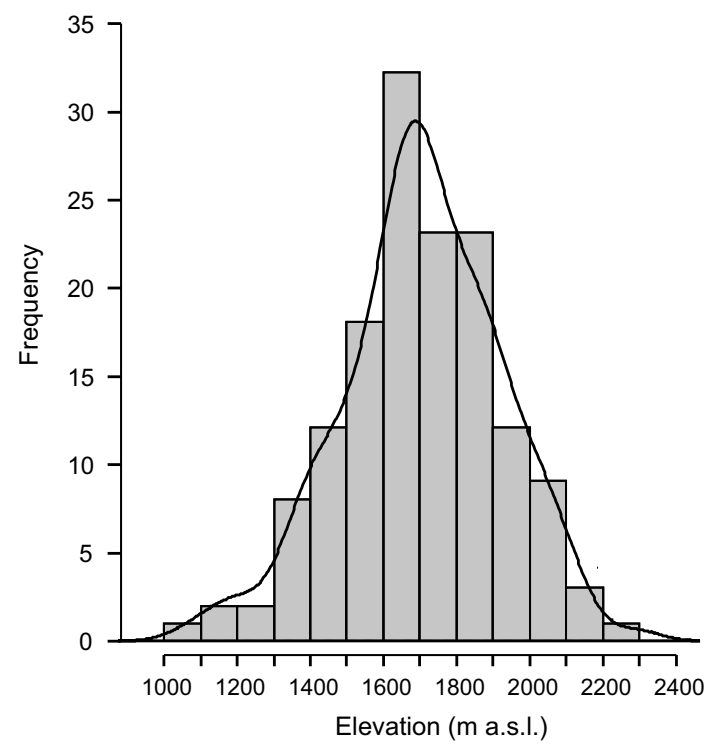

Fig. 2 Elevational distribution of S. minuta in Polish Tatra Mountains based on 147 quasi-random elevational records; line represents nonparametric kernel probability density function (modified from Kiełtyk and Mirek 2017)

\section{Sampling and morphological measurements}

For analysis of phenotypic variation, 1047 plants of $S$. minuta were collected from 47 sites distributed continuously along an elevation gradient of 1070-2120 m a.s.1. Sample sites were selected in a quasi-random fashion; an attempt was made to ensure that they were distributed approximately evenly along the elevational range of the species and that they were representative of all areas
Fig. 1 Location of the 47 sampled elevational sites of $S$. minuta in Polish Tatra Mountains, Western Carpathians. For geographic coordinates and elevations see Table 1

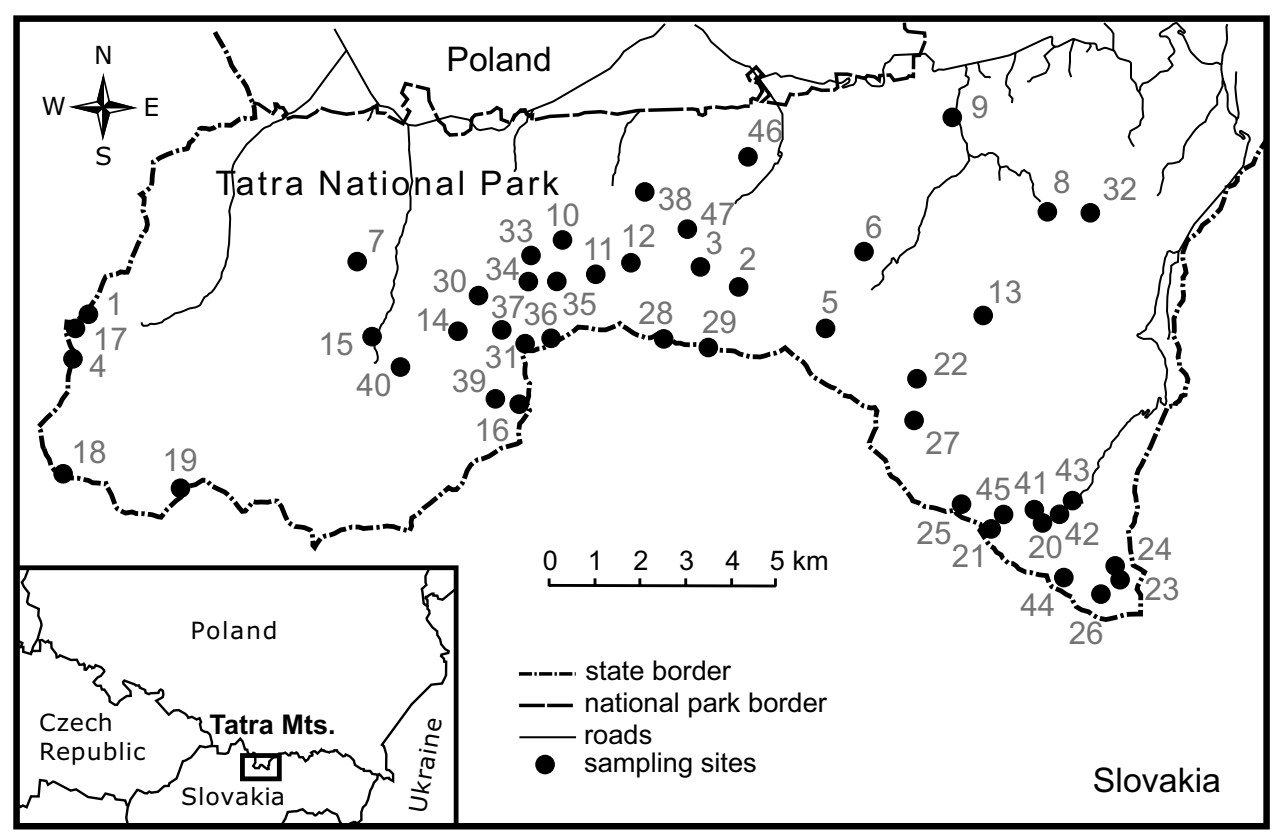


of the Polish-governed Tatra Mountains (Fig. 1; Table 1). The investigated elevational gradient extended from the lower montane belt (here up to $1250 \mathrm{~m}$ a.s.l.), through the upper montane (1250-1550 $\mathrm{m}$ a.s.1.), and the subalpine (1550-1800 $\mathrm{m}$ a.s.1.) to the alpine belt (1800-2300 $\mathrm{m}$ a.s.l.) (Mirek and Piękoś-Mirkowa 1992). Normally, each site sample consisted of $25 \mathrm{~S}$. minuta flowering shoots, but fewer plants were collected in some localities. To ensure that the sampled shoots were separate genets, the minimal distance between the sampled plants was $1 \mathrm{~m}$. Plants were collected in full flower head and flower development (blossom peak) from 2005 to 2008; 27 sites were sampled in 2005, 16 sites in 2006 and additional four in 2007 and 2008 (two sites per year). Morphological traits did not differ substantially between years, with the exception of the sites sampled in 2007 and 2008 due to sampling from different elevational belts in those years. Plants were collected on the sites from relatively small areas, up to ca. $15 \mathrm{~m}$ vertically and ca. $20 \mathrm{~m}$ horizontally. All sampled sites were situated in open, nonforested areas. Below tree line sampling sites were situated in glades or former mountain pastures and were not shaded by a tree canopy. Collected plants were dried and preserved as herbarium specimens for morphometric analyses. Elevational variation in $S$. minuta was examined for the following 12 vegetative and floral traits: plant height measured from the base to the top of inflorescence, middle stem leaf length, number of nodes of the stem from the base to the top of the plant, inflorescence length from the lowest stem node with developed flower head to the top of the inflorescence, inflorescence length relative to plant height, number of flower heads per plant, involucre height from the base of the flower head to the top of the highest bract apices, number of ligulate and tubular flowers per flower head, ligulate flower width and ligulate and tubular flower length. The number of flower heads per plant was counted directly for all sampled plants, whereas traits concerning flower head and flowers were obtained from one randomly chosen, well-developed head per plant from the upper part of the inflorescence, excluding the uppermost head on the shoot apex due to its larger size. The number of ligulate and tubular flowers was counted directly for the chosen flower head, whereas the size of ligulate and tubular flowers was measured for one randomly chosen flower from the head.

To characterize soil conditions associated with stands of $S$. minuta, soil for chemical analyses was sampled for 38 sites located along elevational gradient. Samples were taken from the topsoil to a depth of $15 \mathrm{~cm}$ in places, where $S$. minuta plants were rooted; three to five cores per site were combined to make each sample. The collected soil was air-dried, ground in a ceramic mortar, and passed through a 2-mm-mesh sieve. Soil was analyzed for basic nutrients and soil reaction. Total nitrogen was extracted using the Kjeldahl method, total organic carbon content was determined
Table 1 Sample sites of S. minuta in the Tatra National Park

\begin{tabular}{|c|c|c|c|c|}
\hline Site & $\begin{array}{l}\text { Elevation } \\
\text { (m a.s.l.) }\end{array}$ & Latitude $(\mathrm{N})$ & Longitude (E) & Date \\
\hline 1 & 1500 & $49^{\circ} 14^{\prime} 18.5^{\prime \prime}$ & $019^{\circ} 46^{\prime} 24.0^{\prime \prime}$ & $2005-07-26$ \\
\hline 2 & 1318 & $49^{\circ} 14^{\prime} 46.2^{\prime \prime}$ & $019^{\circ} 58^{\prime} 03.9^{\prime \prime}$ & 2005-07-28 \\
\hline 3 & 1357 & $49^{\circ} 14^{\prime} 55.3^{\prime \prime}$ & $019^{\circ} 57^{\prime} 12.3^{\prime \prime}$ & $2005-07-28$ \\
\hline 4 & 1622 & $49^{\circ} 13^{\prime} 47.5^{\prime \prime}$ & $019^{\circ} 46^{\prime} 07.9^{\prime \prime}$ & 2005-08-18 \\
\hline 5 & 1650 & $49^{\circ} 14^{\prime} 08.2^{\prime \prime}$ & $019^{\circ} 59^{\prime} 40.1^{\prime \prime}$ & $2005-08-03$ \\
\hline 6 & 1563 & $49^{\circ} 15^{\prime} 00.3^{\prime \prime}$ & $020^{\circ} 00^{\prime} 25.2^{\prime \prime}$ & $2005-08-03$ \\
\hline 7 & 1415 & $49^{\circ} 14^{\prime} 55.2^{\prime \prime}$ & $019^{\circ} 51^{\prime} 12.6^{\prime \prime}$ & 2005-08-09 \\
\hline 8 & 1375 & $49^{\circ} 15^{\prime} 31.7^{\prime \prime}$ & $020^{\circ} 03^{\prime} 36.6^{\prime \prime}$ & $2005-08-10$ \\
\hline 9 & 1159 & $49^{\circ} 16^{\prime} 22.9^{\prime \prime}$ & $020^{\circ} 02^{\prime} 05.8^{\prime \prime}$ & 2005-08-10 \\
\hline 10 & 1232 & $49^{\circ} 15^{\prime} 13.4^{\prime \prime}$ & $019^{\circ} 54^{\prime} 52.5^{\prime \prime}$ & $2005-08-12$ \\
\hline 11 & 1460 & $49^{\circ} 14^{\prime} 46.8^{\prime \prime}$ & $019^{\circ} 55^{\prime} 31.7^{\prime \prime}$ & $2005-08-12$ \\
\hline 12 & 1760 & $49^{\circ} 14^{\prime} 55.8^{\prime \prime}$ & $019^{\circ} 56^{\prime} 05.2^{\prime \prime}$ & $2005-08-12$ \\
\hline 13 & 1721 & $49^{\circ} 14^{\prime} 14.3^{\prime \prime}$ & $020^{\circ} 02^{\prime} 25.1^{\prime \prime}$ & $2005-08-13$ \\
\hline 14 & 1380 & $49^{\circ} 13^{\prime} 58.8^{\prime \prime}$ & $019^{\circ} 53^{\prime} 12.8^{\prime \prime}$ & 2005-08-14 \\
\hline 15 & 1073 & $49^{\circ} 13^{\prime} 58.3^{\prime \prime}$ & $019^{\circ} 51^{\prime} 31.8^{\prime \prime}$ & $2005-08-16$ \\
\hline 16 & 1605 & $49^{\circ} 13^{\prime} 19.5^{\prime \prime}$ & $019^{\circ} 53^{\prime} 58.9^{\prime \prime}$ & $2005-08-16$ \\
\hline 17 & 1630 & $49^{\circ} 14^{\prime} 11.2^{\prime \prime}$ & $019^{\circ} 46^{\prime} 03.0^{\prime \prime}$ & 2005-08-18 \\
\hline 18 & 2040 & $49^{\circ} 12^{\prime} 25.9^{\prime \prime}$ & $019^{\circ} 45^{\prime} 52.0^{\prime \prime}$ & 2005-08-18 \\
\hline 19 & 2016 & $49^{\circ} 12^{\prime} 05.9^{\prime \prime}$ & $019^{\circ} 47^{\prime} 58.0^{\prime \prime}$ & 2005-08-18 \\
\hline 20 & 1670 & $49^{\circ} 11^{\prime} 54.3^{\prime \prime}$ & $020^{\circ} 03^{\prime} 30.4^{\prime \prime}$ & $2005-08-22$ \\
\hline 21 & 2120 & $49^{\circ} 11^{\prime} 50.7^{\prime \prime}$ & $020^{\circ} 02^{\prime} 27.5^{\prime \prime}$ & $2005-08-22$ \\
\hline 22 & 1775 & $49^{\circ} 13^{\prime} 32.3^{\prime \prime}$ & $020^{\circ} 01^{\prime} 21.5^{\prime \prime}$ & $2005-08-24$ \\
\hline 23 & 1652 & $49^{\circ} 11^{\prime} 09.6^{\prime \prime}$ & $020^{\circ} 04^{\prime} 49.6^{\prime \prime}$ & $2005-08-25$ \\
\hline 24 & 1590 & $49^{\circ} 11^{\prime} 13.9^{\prime \prime}$ & $020^{\circ} 04^{\prime} 45.0^{\prime \prime}$ & $2005-08-25$ \\
\hline 25 & 1820 & $49^{\circ} 12^{\prime} 08.3^{\prime \prime}$ & $020^{\circ} 01^{\prime} 58.0^{\prime \prime}$ & 2005-08-29 \\
\hline 26 & 1724 & $49^{\circ} 11^{\prime} 02.4^{\prime \prime}$ & $020^{\circ} 04^{\prime} 44.0^{\prime \prime}$ & $2005-08-30$ \\
\hline 27 & 2115 & $49^{\circ} 13^{\prime} 01.7^{\prime \prime}$ & $020^{\circ} 01^{\prime} 14.7^{\prime \prime}$ & 2005-08-31 \\
\hline 28 & 1850 & $49^{\circ} 14^{\prime} 02.7^{\prime \prime}$ & $019^{\circ} 56^{\prime} 37.6^{\prime \prime}$ & 2006-08-12 \\
\hline 29 & 1880 & $49^{\circ} 13^{\prime} 55.2^{\prime \prime}$ & $019^{\circ} 57^{\prime} 24.5^{\prime \prime}$ & 2006-08-12 \\
\hline 30 & 1697 & $49^{\circ} 14^{\prime} 34.1^{\prime \prime}$ & $019^{\circ} 53^{\prime} 24.6^{\prime \prime}$ & 2006-08-16 \\
\hline 31 & 2090 & $49^{\circ} 13^{\prime} 52.9^{\prime \prime}$ & $019^{\circ} 54^{\prime} 15.1^{\prime \prime}$ & 2006-08-16 \\
\hline 32 & 1446 & $49^{\circ} 15^{\prime} 28.2^{\prime \prime}$ & $020^{\circ} 04^{\prime} 18.6^{\prime \prime}$ & 2006-08-18 \\
\hline 33 & 1411 & $49^{\circ} 14^{\prime} 54.2^{\prime \prime}$ & $019^{\circ} 54^{\prime} 18.5^{\prime \prime}$ & 2006-08-21 \\
\hline 34 & 1531 & $49^{\circ} 14^{\prime} 36.8^{\prime \prime}$ & $019^{\circ} 54^{\prime} 26.4^{\prime \prime}$ & 2006-08-21 \\
\hline 35 & 1802 & $49^{\circ} 14^{\prime} 40.1^{\prime \prime}$ & $019^{\circ} 54^{\prime} 47.5^{\prime \prime}$ & 2006-08-22 \\
\hline 36 & 2044 & $49^{\circ} 13^{\prime} 59.5^{\prime \prime}$ & $019^{\circ} 54^{\prime} 49.9^{\prime \prime}$ & 2006-08-22 \\
\hline 37 & 1872 & $49^{\circ} 14^{\prime} 09.2^{\prime \prime}$ & $019^{\circ} 53^{\prime} 47.4^{\prime \prime}$ & 2006-08-22 \\
\hline 38 & 1320 & $49^{\circ} 15^{\prime} 48.2^{\prime \prime}$ & $019^{\circ} 56^{\prime} 32.8^{\prime \prime}$ & 2006-08-24 \\
\hline 39 & 1481 & $49^{\circ} 13^{\prime} 17.9^{\prime \prime}$ & $019^{\circ} 53^{\prime} 45.5^{\prime \prime}$ & $2006-08-26$ \\
\hline 40 & 1165 & $49^{\circ} 13^{\prime} 40.8^{\prime \prime}$ & $019^{\circ} 51^{\prime} 56.2^{\prime \prime}$ & 2006-08-26 \\
\hline 41 & 1775 & $49^{\circ} 11^{\prime} 57.5^{\prime \prime}$ & $020^{\circ} 03^{\prime} 22.1^{\prime \prime}$ & 2006-08-28 \\
\hline 42 & 1520 & $49^{\circ} 11^{\prime} 55.7^{\prime \prime}$ & $020^{\circ} 03^{\prime} 51.4^{\prime \prime}$ & 2006-08-28 \\
\hline 43 & 1435 & $49^{\circ} 12^{\prime} 05.1^{\prime \prime}$ & $020^{\circ} 04^{\prime} 04.4^{\prime \prime}$ & 2006-08-28 \\
\hline 44 & 1901 & $49^{\circ} 11^{\prime} 13.6^{\prime \prime}$ & $020^{\circ} 03^{\prime} 57.8^{\prime \prime}$ & $2007-08-22$ \\
\hline 45 & 1860 & $49^{\circ} 11^{\prime} 52.1^{\prime \prime}$ & $020^{\circ} 03^{\prime} 04.5^{\prime \prime}$ & 2007-08-27 \\
\hline 46 & 1220 & $49^{\circ} 16^{\prime} 06.4^{\prime \prime}$ & $019^{\circ} 58^{\prime} 19.0^{\prime \prime}$ & 2008-08-17 \\
\hline 47 & 1582 & $49^{\circ} 15^{\prime} 17.9^{\prime \prime}$ & $019^{\circ} 57^{\prime} 14.3^{\prime \prime}$ & 2008-08-21 \\
\hline
\end{tabular}

Geographic coordinates are in accordance with WGS84 geodetic system 
using a LECO CR-12 Carbon Analyzer and plant-available phosphorus was determined by the Egner-Riehm method. Metallic cations were leached in ammonium acetate solution; exchangeable potassium was determined using atomic emission spectrometry (AES), and exchangeable magnesium and exchangeable calcium using atomic absorption spectroscopy (AAS) with atomization by an air-acetylene flame (Mg) and by an acetylene-nitrous oxide flame (Ca).

\section{Data analysis}

Morphological variation in S. minuta along an elevational gradient was analyzed with linear mixed-effects models (Field et al. 2013). Morphological traits were averaged for each site, and mean values were used in models computation. To test whether the data were spatially auto-correlated, what could violate assumptions of linear models (Borcard et al. 2011), three methods for detection of autocorrelation were applied: (1) Moran's I spatial autocorrelation coefficient, (2) Mantel test for correlation between geographic distance and trait distance matrices (with $n=9999$ permutations), and (3) building mixed-effects models without spatial structures and with spatial correlation structures (exponential and Gaussian) included and assessment fit of these models according to Akaike's Information Criterion (AIC) and Bayesian Information Criterion (BIC) (Zuur et al. 2009). Lower AIC and $\mathrm{BIC}$ values correspond to model better fitted to the data. Moran's I coefficient indicated that from the set of 12 morphological traits three, i.e. plant height, number of flower heads, and number of tubular flower per head, were spatially auto-correlated (Table 2a). Mantel test for correlation between morphological traits and geographical distances did not detect existence of spatial correlation in the data, except for a slight spatial correlation in middle leaf length $(r=0.1250, p$ value $=0.044)$ (Table 2b). Comparison of null models with spatial structures for all traits, based on AIC and BIC values, indicated that including in model term for spatial correlation did not improve considerably goodness of fit of these models (Table 2c). Based on results of these three tests for spatial autocorrelation, the conclusion was made that morphological traits were not spatially auto-correlated. In the next step, the effect of elevation on morphological traits was tested by comparing model with linear fixed term $Y=a+b_{1} \times($ elevation $)$, and model with quadratic fixed term $Y=a+b_{1} \times($ elevation $)+b_{2} \times(\text { elevation })^{2}$, where $a$ denotes an intercept and $b_{1}$ and $b_{2}$ denote regression coefficients. In both these models, year of sample collection was specified as a random effect to control for possible year effect. Because in 2007 and 2008 only four samples were collected (two per year), these samples were included in 2006 year. To compare linear and quadratic models, likelihood ratio test was calculated, in which $p$ value $<0.05$ expressed significant improvement of the linear model once the quadratic term was added. Additionally, for evaluation of both models Akaike's Information Criterion and Bayesian Information Criterion were calculated. To test whether soil characteristics of the sampled sites were correlated with elevation, Pearson correlation coefficients and simple linear regression were calculated for

Table 2 Results of spatial autocorrelation analyses

\begin{tabular}{|c|c|c|c|c|c|c|c|c|c|c|}
\hline \multirow[t]{3}{*}{ Trait } & \multicolumn{2}{|l|}{$\mathrm{a}$} & \multicolumn{2}{|l|}{$\mathrm{b}$} & \multicolumn{6}{|l|}{ c } \\
\hline & \multirow[t]{2}{*}{ Moran's I } & \multirow[t]{2}{*}{$p$ value } & \multirow[t]{2}{*}{ Mantel statistic } & \multirow[t]{2}{*}{$p$ value } & \multicolumn{3}{|l|}{ AIC } & \multicolumn{3}{|l|}{ BIC } \\
\hline & & & & & Null & Expon & Gauss & Null & Expon & Gauss \\
\hline Plant height & 0.0774 & 0.0203 & 0.0485 & 0.2207 & 570.9 & 558.2 & 564.4 & 576.5 & 565.6 & 571.8 \\
\hline Middle leaf length & 0.0045 & 0.5377 & 0.1250 & 0.0440 & 436.5 & 430.7 & 428.9 & 442.1 & 438.1 & 436.3 \\
\hline No. stem nodes & 0.0467 & 0.1108 & 0.0738 & 0.1195 & 224.0 & 222.9 & 226.0 & 229.6 & 230.3 & 233.4 \\
\hline Inflorescence length & 0.0163 & 0.3702 & -0.0107 & 0.5189 & 512.4 & 510.1 & 511.4 & 517.9 & 517.5 & 518.8 \\
\hline Inflorescence length/plant height & 0.0166 & 0.3679 & 0.1157 & 0.0592 & -90.1 & -92.0 & -94.8 & -84.5 & -84.6 & -87.4 \\
\hline No. flower heads & 0.0673 & $\mathbf{0 . 0 3 7 7}$ & 0.0302 & 0.2751 & 372.6 & 370.9 & 374.2 & 378.2 & 378.3 & 381.6 \\
\hline Involucre height & 0.0142 & 0.3990 & 0.0418 & 0.2537 & 73.4 & 70.7 & 72.9 & 79.0 & 78.1 & 80.3 \\
\hline No. tubular flowers & 0.1054 & 0.0030 & 0.0358 & 0.2634 & 243.9 & 242.3 & 244.5 & 249.4 & 249.7 & 251.9 \\
\hline No. ligulate flowers & 0.0608 & 0.0531 & 0.0173 & 0.3597 & 133.5 & 130.0 & 130.7 & 139.0 & 137.4 & 138.1 \\
\hline Ligule width & 0.0065 & 0.5108 & 0.0014 & 0.4562 & -32.5 & -30.7 & -30.6 & -27.0 & -23.3 & -23.2 \\
\hline Ligulate flower length & 0.0379 & 0.1626 & -0.0524 & 0.7781 & 103.9 & 100.5 & 103.8 & 109.5 & 107.9 & 111.2 \\
\hline Tubular flower length & 0.0006 & 0.6039 & -0.0564 & 0.8236 & 27.1 & 27.0 & 28.9 & 32.6 & 34.4 & 36.3 \\
\hline
\end{tabular}

a-Moran's $I$ autocorrelation coefficient and $p$ value of the test of null hypothesis of no spatial autocorrelation in morphological traits, b-Mantel test of the correlation between geographic distance and trait distance matrices and $p$ value of the test of null hypothesis of no correlation between these matrices. c-Evaluation of goodness of fit of models with no term for spatial correlation (Null) and models with exponential (Expon), and Gaussian (Gauss) spatial correlation structures included 
each soil parameter. All statistical analyses were performed in $\mathrm{R}$ version 3.4.2 (R Core Team 2017). Linear mixed-effects models were calculated using $\operatorname{lme}($ ) function from the package 'nlme' (Pinheiro et al. 2017), Moran's I spatial autocorrelation coefficient was calculated using Moran.I() function of the 'ape' package (Paradis et al. 2004), and Mantel test was calculated with the use of mantel.rtest() function from the 'ade4' package (Dray and Dufour 2007).

\section{Results}

Results of the analysis of soil characteristics of S. minuta sample sites indicated that none of the investigated soil parameters was significantly correlated with elevation (Fig. 3). Nearly all of the investigated morphological traits of S. minuta changed significantly along a $1000 \mathrm{~m}$
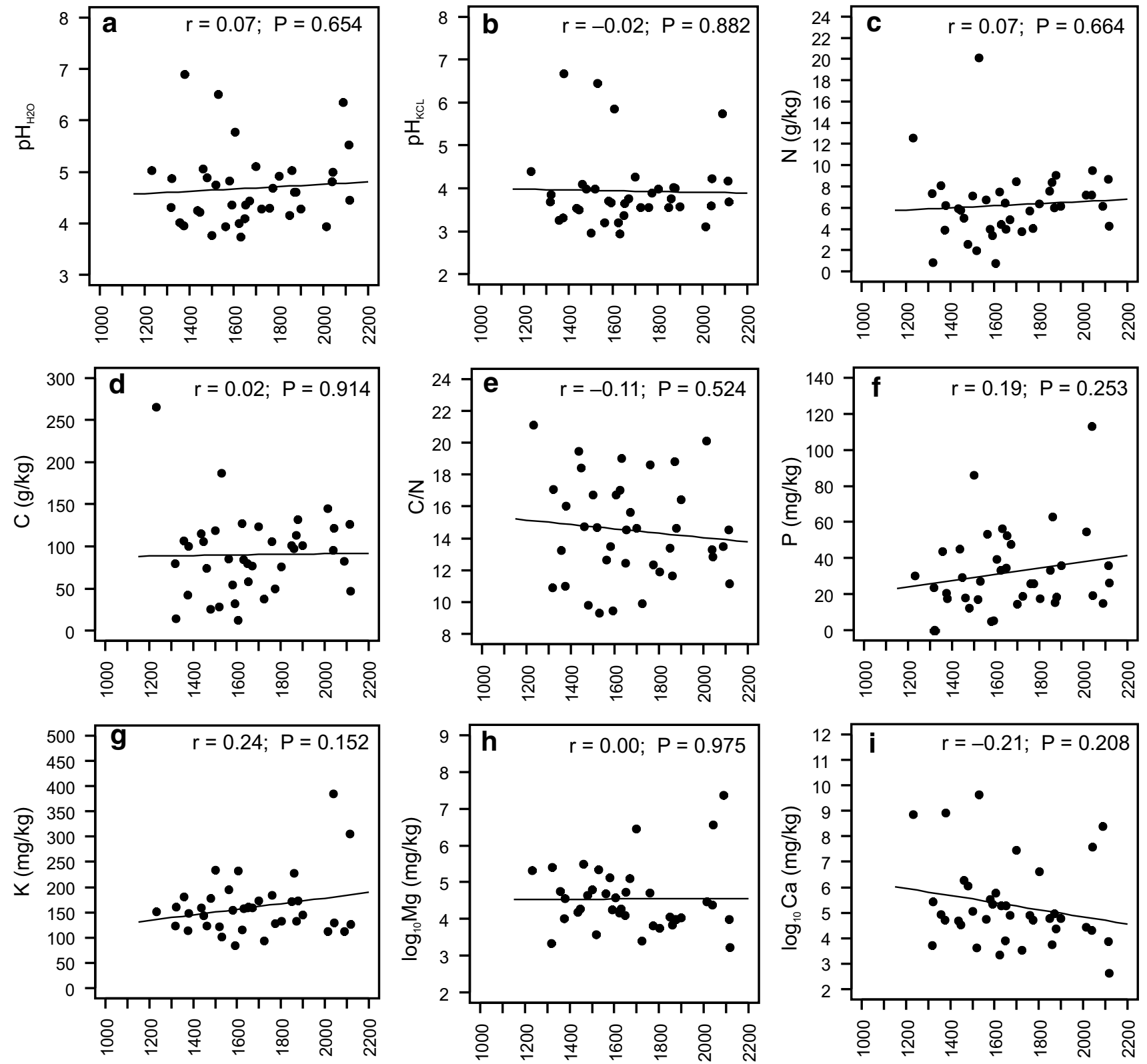

Elevation ( $m$ a.s.I.)

Fig. 3 Variation in soil parameters of $S$. minuta sites along elevational gradient; a acidity in $\mathrm{H}_{2} \mathrm{O}$ solution, b acidity in KCL solution, c nitrogen content, $\mathbf{d}$ carbon content, e $\mathrm{C} / \mathrm{N}$ ratio, $\mathbf{f}$ phosphorus content, $\mathbf{g}$ potassium content, $\mathbf{f}$ magnesium content, $\mathbf{i}$ calcium content. $r$ Pearson correlation coefficient, $P p$ value of the significance test for the Pearson correlation coefficient. Line represents simple linear regression 

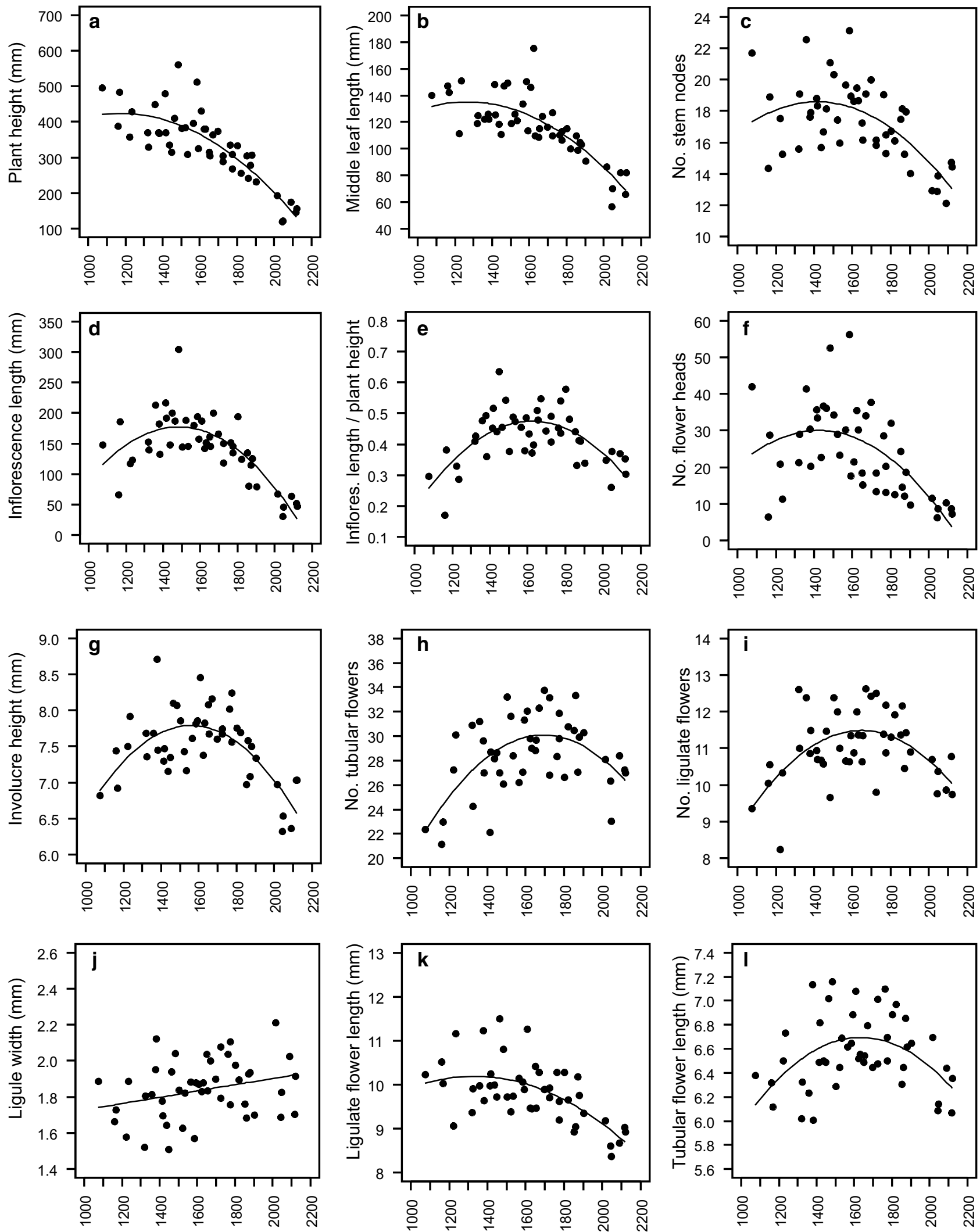

Elevation (m a.s.I.)

Fig. 4 Elevational variation in morphological traits of $S$. minuta; a plant height, $\mathbf{b}$ middle leaf length, $\mathbf{c}$ number of stem nodes, $\mathbf{d}$ inflorescence length, $\mathbf{e}$ inflorescence length/plant height ratio, $\mathbf{f}$ number of flower heads, $\mathbf{g}$ involu- cre height, $\mathbf{h}$ number of tubular flowers, $\mathbf{i}$ number of ligulate flowers, $\mathbf{j}$ ligule width, k ligulate flower length, $\mathbf{I}$ tubular flower length. Dots represent traits averaged per elevational site; line represents fitted model 
elevational gradient (Fig. 4). All of these traits, except one (Fig. $4 \mathrm{j}$ ), were considerably better fitted to elevation by a model with the quadratic term than by a linear model (Table 3). Traits attributed to vegetative growth, such as plant height, leaf length and number of shoot nodes, did not change considerably from the lowest elevations up to ca. $1400-1500 \mathrm{~m}$ a.s.l., but, above $1500 \mathrm{~m}$ a.s.l., they began to decrease at a high rate with the increase in elevation (Fig. 4a-c). Linear model calculated for the elevational range of 1500-2120 $\mathrm{m}$ a.s.l. revealed that the fitted plant height decreased in this range from 418 to $146 \mathrm{~mm}$, at the rate of $43.7 \mathrm{~mm}$ per every $100 \mathrm{~m}$ of increased elevation; that is equivalent to a decrease of $79.4 \mathrm{~mm}$ for a $1 \mathrm{~K}$ decrease of mean annual temperature, assuming a decrease in temperature by $0.55 \mathrm{~K}$ per every $100 \mathrm{~m}$ increase in elevation (Körner 2007). Size of inflorescence, as expressed by its length, was highest at the centre of the elevational range of the species. Absolute length of inflorescence increased from low elevational positions up to ca. $1500 \mathrm{~m}$ a.s.l. and began to decrease above this elevation (Fig. 4d), but inflorescence length relative to plant height continued to increase up to ca. $1600 \mathrm{~m}$ a.s.l., and above this elevation it began to decrease (Fig. 4e). The number of flower heads per plant decreased at higher elevations, having its maximum at the centre of the investigated gradient (Fig. 4f). Flower heads were largest at intermediate elevation. Involucre height and number of tubular and ligulate flowers had their maxima at elevations from 1400 to $1800 \mathrm{~m}$ a.s.l. (Fig. 4g-i). Ligule width varied greatly along elevational gradient; the linear model was significantly better fitted for this trait than the model with quadratic term (Fig. 4j). Ligulate flower length did not change considerably from low to intermediate elevations, but, above ca. $1600-1700 \mathrm{~m}$ a.s.1., a decrease with increasing elevation was observed also in this trait (Fig. 4k). The size of tubular flowers, expressed by their length, was largest at the centre of the elevational range of the species, that is, from ca. 1500 to $1800 \mathrm{~m}$ a.s.l., and this decreased at higher and lower elevations (Fig. 41).

\section{Discussion}

Results of the above ground performance analysis of the alpine plant $S$. minuta along a $1000 \mathrm{~m}$ elevational gradient in the Tatra Mountains show that nearly all of the investigated fitness-related floral traits of $S$. minuta, that is, relative size of inflorescence, number and size of flower heads, and number and size of individual flowers, were better fitted by the model with the quadratic term than by the linear model, and expressed unimodal relationships with elevation having their maxima in the centre of the elevational distribution of this species. This suggest the existence of a local optimum with respect to sexual reproduction at the centre of the elevational range of the species. Elevational variation in traits related to vegetative growth, such as plant height, leaf length and number of shoot nodes was also best fitted by the model with the quadratic term. Initially, from low to intermediate elevations, there was no considerable change in their values, but, from the intermediate elevation upwards, the reduction of plant size was observed. Measured soil parameters of $S$. minuta sample sites varied greatly and did not express any clear trend with elevation. This suggest that observed pattern of elevational variation in S. minuta was not influenced by soil characteristics.

The results presented here are in line with the results of Malo and Baonza (2002) who, in the study on plant-pollinator interactions along an elevational gradient, found that

Table 3 Linear mixed-effects models summaries; model 1 with linear fixed term $Y=a+b_{1} \times$ (elevation) and model 2 with quadratic fixed term $Y=a+b_{1} \times($ elevation $)+b_{2} \times(\text { elevation })^{2}$

\begin{tabular}{llllccc}
\hline$Y$ & Intercept $(a)$ & $b_{1}$ & $b_{2}$ & AIC $_{\text {model } 1 / \text { model2 }}$ & BIC $_{\text {model } / \text { model2 }}$ & Likelihood ratio test \\
\hline Plant height (mm) & $-268.23 \times 10^{-01}$ & $766.84 \times 10^{-03}$ & $-3.26 \times 10^{-04}$ & $525.3 / 517.0$ & $532.7 / 526.2$ & $10.29 ; p=0.0013$ \\
Middle leaf length (mm) & $-113.56 \times 10^{-01}$ & $231.35 \times 10^{-03}$ & $-9.1 \times 10^{-05}$ & $400.7 / 391.1$ & $408.1 / 400.4$ & $11.56 ; p=0.0007$ \\
Number of stem nodes & $-370.16 \times 10^{-02}$ & $315.19 \times 10^{-03}$ & $-1.1 \times 10^{-05}$ & $211.6 / 204.2$ & $219.0 / 213.4$ & $9.41 ; p=0.0022$ \\
Inflorescence length (mm) & $-637.73 \times 10^{+00}$ & $109.93 \times 10^{-02}$ & $-4.0 \times 10^{-04}$ & $498.2 / 472.0$ & $505.6 / 481.3$ & $28.20 ; p<0.0001$ \\
Inflorescence length/plant height & $-143.07 \times 10^{-02}$ & $234.77 \times 10^{-05}$ & $-7.0 \times 10^{-07}$ & $-88.1 /-114.1$ & $-80.7 /-104.9$ & $28.04 ; p<0.0001$ \\
No. of flower heads per plant & $-787.91 \times 10^{-01}$ & $153.15 \times 10^{-03}$ & $-5.0 \times 10^{-05}$ & $361.7 / 354.6$ & $369.1 / 363.8$ & $9.105 ; p=0.0025$ \\
Involucre height (mm) & $-158.91 \times 10^{-02}$ & $120.38 \times 10^{-04}$ & $-3.9 \times 10^{-06}$ & $69.2 / 40.7$ & $76.6 / 49.9$ & $30.57 ; p<0.0001$ \\
No. of tubular flowers per head & $-286.67 \times 10^{-01}$ & $693.55 \times 10^{-04}$ & $-2.0 \times 10^{-05}$ & $243.0 / 227.3$ & $250.4 / 236.6$ & $17.70 ; p<0.0001$ \\
No. of ligulate flowers per head & $-605.75 \times 10^{-02}$ & $213.11 \times 10^{-04}$ & $-6.0 \times 10^{-06}$ & $135.2 / 119.7$ & $142.6 / 129.0$ & $17.50 ; p<0.0001$ \\
Ligule width (mm) & $155.36 \times 10^{-02}$ & $174.60 \times 10^{-06}$ & - & $-36.4 /-35.1$ & $-29.0 /-25.8$ & $0.73 ; p=0.3941$ \\
Ligulate flower length (mm) & $592.33 \times 10^{-02}$ & $641.20 \times 10^{-05}$ & $-2.0 \times 10^{-06}$ & $88.4 / 84.5$ & $95.8 / 93.8$ & $5.86 ; p=0.0155$ \\
Tubular flower length (mm) & $191.59 \times 10^{-02}$ & $584.75 \times 10^{-05}$ & $-1.8 \times 10^{-06}$ & $29.1 / 18.9$ & $36.5 / 28.2$ & $12.13 ; p=0.0005$ \\
\hline
\end{tabular}

Degree of freedom $(d f)-44$ for model 1, and 43 for model 2 
the flower size of Cytisus scoparius in the mountains of Central Spain had a unimodal relationship with elevation. The increase in flower size in conspecific populations of insect-pollinated plants with increasing elevation has been explained by pollinator selection for larger flowers at high elevation, where pollinators are rare but generally have a larger size (e.g. Malo and Baonza 2002; Maad et al. 2013). Such an increase in the size of floral structures, e.g. flowers, flower heads and inflorescences, is considered to be advantageous for insect-pollinated plants because this increases the chances of attracting pollinators and producing viable seeds (Ohara and Higashi 1994). However, Zhao and Wang (2015) found that, despite lower pollinator availability at high elevations and the existence of strong selection by pollinators for larger flowers, the flower size of Trollius ranunculoides decreased significantly towards higher elevations. This decrease in flower size was explained in the context of the 'resource-cost compromise' hypothesis, according to which smaller flowers are advantageous in unfavourable environmental conditions due to the lower cost of their development and maintenance (Herrera 2005). The abiotic selection for smaller flowers at higher elevations could prevent a response in flower size to selection from pollinators (Totland 2001, 2004; Zhao and Wang 2015). Perhaps, there is a trade-off between response to pollinator selection and adaptation to environmental, potentially selective factors associated with changes in elevation, such as, among others, low temperature, strong winds and short growing season at high elevations. Result of this trade-off may be responsible for the existence of unimodal relationships between floral traits of some species and elevation; from low to intermediate elevations, selection by pollinators for larger inflorescences and larger flower heads might prevail, whereas in environmental conditions of high elevations, plant growth and size may be constrained partly as a result of phenotypic plasticity, and partly by climatic selection for smaller phenotypes which are advantageous due to lower resource requirements, as proposed by the 'resource-cost compromise' hypothesis (Herrera 2005; Zhao and Wang 2015).

It is also worth noting that the results of this study seem to support the 'centre-periphery' hypothesis and the 'abundant centre model' (Hengeveld and Haeck 1982; Brown 1984; Jump and Woodward 2003; Herrera and Bazaga 2008; Vaupel and Matthies 2012), both predicting that populations from the centre of the species range perform better than marginal populations. Accordingly, $S$. minuta was found to be most frequent in the centre of its elevational distribution (Kiełtyk and Mirek 2017) and produced its largest inflorescences, flower heads and flowers, as well as its highest number of flowers per head, in the centre of its elevational range. Although the reproductive success of $S$. minuta was not investigated in this study, the pattern of morphological variation in fitness-related floral traits may suggest that the species performs best at the centre of its elevational range and achieves a local optimum there. This result is consistent, for example, with a recent study on elevational divergence in two Aquilegia vulgaris subspecies in the southern Iberian Peninsula in which both taxa performed better at their central elevational range then at the periphery (Bastida et al. 2015). Similarly, Angert and Schemske (2005) found that two species, Mimulus cardinalis and M. lewisii, growing at different elevation ranges in North America, were both best fitted in the centre of their elevational ranges. With regard to the elevational limits of $S$. minuta distribution, the upper limit, as with other alpine plants, is most probably determined by abiotic factors, while the lower limit is likely controlled predominantly by biotic factors, particularly high inter-specific competition at early stages, i.e. seedlings (Billings and Mooney 1968; Weppler and Stöcklin 2005).

Significant unimodal relationships between fitnessrelated inflorescence and floral traits of $S$. minuta and elevation suggest that, at the centre of an elevational range, there exists a local optimum in terms of the development of floral structures for sexual reproduction. It should be noted, however, that this study cannot render a definitive statement as to the causes of the observed pattern of morphological variation and to what degree the observed changes represent genetic differences of locally adapted populations or plastic, environmentally induced responses across the elevation gradient. Moreover, in addition to climatic factors and pollinator selection pressure, there are other possible factors, e.g. herbivory, competition, or habitat and vegetation conditions and characteristics, which may also be responsible for the observed pattern of elevational variation in $S$. minuta. Models of elevational variations in morphological traits have rarely been the subject of previous studies, and it is difficult to determine if the unimodal changes in floral traits along the elevational gradient that were observed in $S$. minuta represent a wider pattern in alpine plants. It is possible that unimodal changes in morphological traits may be observed only in plant species with wide vertical ranges, as a result of different selection pressures operating at low and high elevations, whereas species with a narrow elevational range may exhibit only decreasing or increasing monotonic changes with elevation, as a result of dominant selection pressure at given elevations. Further studies investigating variations in plant species with wide, as well as narrow or more restricted elevational ranges are necessary to be able to comment on the generality of the revealed elevational patterns in alpine species.

Acknowledgements I thank the authorities of the Tatra National Park for allowing to conduct the study and collect plant material. I kindly 
acknowledge two anonymous reviewers for constructive comments on previous versions of the manuscript. This work was supported financially by the Polish State Committee for Scientific Research (Grant N303 028 31/0845) and by the Cardinal Stefan Wyszyński University in Warsaw.

\section{Compliance with ethical standards}

Conflict of interest The author declares that he has no conflict of interest.

Open Access This article is distributed under the terms of the Creative Commons Attribution 4.0 International License (http://creativecommons.org/licenses/by/4.0/), which permits unrestricted use, distribution, and reproduction in any medium, provided you give appropriate credit to the original author(s) and the source, provide a link to the Creative Commons license, and indicate if changes were made.

\section{References}

Alexander JM, Edwards PJ et al (2009) Establishment of parallel clines in traits of native and introduced forbs. Ecology 90:612-622. https://doi.org/10.1890/08-0453.1

Angert AL, Schemske DW (2005) The evolution of species' distributions: reciprocal transplants across the elevational ranges of Mimulus cardinalis and M. lewisii. Evolution 59:1671-1684. https://doi.org/10.1111/j.0014-3820.2005.tb01817.x

Baret S, Maurice S et al (2004) Altitudinal variation in fertility and vegetative growth in the invasive plant Rubus alceifolius Poiret (Rosaceae), on Réunion island. Plant Ecol 172:265-273. https:// doi.org/10.1023/B:VEGE.0000026345.67250.d2

Bastida JM, Rey PJ et al (2015) Local adaptation to distinct elevational cores contributes to current elevational divergence of two Aquilegia vulgaris subspecies. J Plant Ecol 8:273-283. https:// doi.org/10.1093/jpe/rtu017

Billings WD (1974) Arctic and alpine vegetation: plant adaptations to cold summer climates. In: Ives JD, Barry RG (eds) Arctic and alpine environments. Methuen, London, pp 403-443

Billings WD, Mooney HA (1968) The ecology of arctic and alpine plants. Biol Rev 43:481-529. https://doi.org/10.1111/j.1469185X.1968.tb00968.x

Blionis GJ, Vokou D (2002) Structural and functional divergence of Campanula spatulata subspecies on Mt Olympos (Greece). Plant Syst Evol 232:89-105. https://doi.org/10.1007/s006060200029

Borcard D, Gillet F et al (2011) Numerical ecology with R. Springer, New York. https://doi.org/10.1007/978-1-4419-7976-6

Brown JH (1984) On the relationship between abundance and distribution of species. Am Nat 124:255-279. https://doi. org/10.1086/284267

Clausen J, Keck DD et al (1948) Experimental studies on the nature of species. III. Environmental responses of climatic races of Achillea. Carnegie Institution of Washington, Washington, DC (Publication 581)

Dray S, Dufour AB (2007) The ade4 package: implementing the duality diagram for ecologists. J Stat Softw 22:1-20. https://doi. org/10.18637/jss.v022.i04

Fabbro T, Körner Ch (2004) Altitudinal differences in flower traits and reproductive allocation. Flora 199:70-81. https://doi. org/10.1078/0367-2530-00128
Felde VA, Kapfer J et al (2012) Upward shift in elevational plant species ranges in Sikkilsdalen, Central Norway. Ecography 35:922932. https://doi.org/10.1111/j.1600-0587.2011.07057.x

Field A, Miles J et al (2013) Discovering statistics using R. Sage Publications Ltd, London

Frei ER, HahnT et al (2014a) Divergent selection in low and high elevation populations of a perennial herb in the Swiss Alps. Alp Botany 124:131-142. https://doi.org/10.1007/s00035-014-0131-1

Frei ER, Ghazoul J et al (2014b) Plant population differentiation and climate change: responses of grassland species along an elevational gradient. Glob Change Biol 20:441-455. https://doi. org/10.1111/gcb.12403

Gonzalo-Turpin H, Hazard L (2009) Local adaptation occurs along altitudinal gradient despite the existence of gene flow in the alpine plant species Festuca eskia. J Ecol 97:742-751. https:// doi.org/10.1111/j.1365-2745.2009.01509.x

Gugger S, Kesselring H et al (2015) Lower plasticity exhibited by high- versus mid-elevation species in their phenological responses to manipulated temperature and drought. Ann Bot 116:953-962. https://doi.org/10.1093/aob/mcv155

Guo H, Mazer SJ et al (2010) Geographic variation in seed mass within and among nine species of Pedicularis (Orobanchaceae): effects of elevation, plant size and seed number per fruit. J Ecol 98:1232-1242. https://doi. org/10.1111/j.1365-2745.2010.01688.x

Hamann E, Kesselring H et al (2016) Evidence of local adaptation to fine- and coarse-grained environmental variability in Poa alpina in the Swiss Alps. J Ecol 104:1627-1637. https://doi. org/10.1111/1365-2745.12628

Hautier Y, Randin ChF et al (2009) Changes in reproductive investment with altitude in an alpine plant. J Plant Ecol 2:125-134. https:// doi.org/10.1093/jpe/rtp01

Hengeveld R, Haeck J (1982) The distribution of abundance. I. Measurements. J Biogeogr 9:303-316. https://doi.org/10.2307/2844717

Herrera J (2005) Flower size variation in Rosmarinus officinalis: individuals, populations and habitats. Ann Bot 95:431-437. https:// doi.org/10.1093/aob/mci041

Herrera CM, Bazaga P (2008) Adding a third dimension to the edge of a species' range: altitude and genetic structuring in mountainous landscapes. Heredity 100:275-285. https://doi.org/10.1038/ sj.hdy.6801072

Hess M (1996) Climate. In: Mirek Z (ed) The nature of the Tatra National Park. Tatrzański Park Narodowy. Zakopane, Kraków, pp 53-68 (Polish with English summary)

Hirano M, Sakaguchi S et al (2017) Phenotypic differentiation of the Solidago virgaurea complex along an elevational gradient: insights from a common garden experiment and population genetics. Ecol Evol 7:6949-6962. https://doi.org/10.1002/ece3.3252

Jump AS, Woodward FI (2003) Seed production and population density decline approaching the range-edge of Cirsium species. New Phytol 160:349-358. https://doi. org/10.1046/j.1469-8137.2003.00873.x

Kelly CA (1998) Effects of variable life history and insect herbivores on reproduction in Solidago macrophylla (Asteraceae) on an elevational gradient. Am Midl Nat 139:243-254. https://doi. org/10.1674/0003-0031(1998)139[0243:EOVLHA]2.0.CO;2

Kiełtyk P, Mirek Z (2014) Taxonomy of the Solidago virgaurea group (Asteraceae) in Poland, with special reference to variability along an altitudinal gradient. Folia Geobot 49:259-282. https://doi. org/10.1007/s12224-013-9180-2

Kiełtyk P, Mirek Z (2017) Distribution and ecology of high-mountain Solidago minuta (Asteraceae) in Poland. Biologia 72:161-174. https://doi.org/10.1515/biolog-2017-0017

Kim E, Donohue K (2013) Local adaptation and plasticity of Erysium capitatum to altitude: its implications for responses 
to climate change. J Ecol 101:796-805. https://doi. org/10.1111/1365-2745.12077

Körner Ch (2003) Alpine plant life. Functional plant ecology of high mountain ecosystems, 2 ed. Springer, Berlin. https://doi. org/10.1007/978-3-642-18970-8

Körner Ch (2007) The use of 'altitude' in ecological research. Trends Ecol Evol 22:569-574. https://doi.org/10.1016/j.tree.2007.09.006

Körner Ch, Renhardt U (1987) Dry matter partitioning and root length/ leaf area ratios in herbaceous perennial plants with diverse altitudinal distribution. Oecologia 74:411-418. https://doi.org/10.1007/ BF00378938

Kudo G, Molau U (1999) Variations in reproductive traits at inflorescence and flower levels of an arctic legume, Astragalus alpinus L.: comparisions between a subalpine and an alpine population. Plant Species Biol 14:181-191. https://doi. org/10.1046/j.1442-1984.1999.00012.x

Ma WL, Shi PL et al (2010) Changes in individual plant traits and biomass allocation in alpine meadow with elevation variation on the Qinghai-Tibetan Plateau. Sci China Life Sci 53:1142-1151. https://doi.org/10.1007/s11427-010-4054-9

Maad J, Armbruster WS et al (2013) Floral size variation in Campanula rotundifolia (Campanulaceae) along altitudinal gradients: patterns and possible selective mechanisms. Nord J Bot 31:361-371. https://doi.org/10.1111/j.1756-1051.2013.01766.x

Malo JE, Baonza J (2002) Are there predictable clines in plant-pollinator interactions along altitudinal gradients? The example of Cytisus scoparius (L.) Link in the Sierra de Guadarrama (Central Spain). Divers Distrib 8:365-371. https://doi. org/10.1046/j.1472-4642.2002.00161.x

Mirek Z, Piękoś-Mirkowa H (1992) Plant cover of the Polish Tatra Mountains (S. Poland). Veröff. Geobot. Inst, 107. ETH, Stiftung Rübel, Zürich, pp 177-199

Montesinos-Navarro A, Wig J et al (2011) Arabidopsis thaliana populations show clinal variation in a climatic gradient associated with altitude. New Phytol 189:282-294. https://doi. org/10.1111/j.1469-8137.2010.03479.x

Neuffer B, Bartelheim S (1989) Gen-ecology of Capsella bursa-pastoris from an altitudinal transsect in the Alps. Oecologia 81:521527. https://doi.org/10.1007/BF00378963

Nishizawa T, Kinoshita E et al (2001) Morphological variation of the head characters in Solidago virgaurea L. inhabiting three mountains in central Honshu. J Phytogeogr Taxon 49:117-127

Ohara M, Higashi S (1994) Effects of inflorescence size on visits from pollinators and seed set of Corydalis ambigua (Papaveraceae). Oecologia 98:25-30. https://doi.org/10.1007/BF00326086

Paradis E, Claude J et al (2004) APE: analyses of phylogenetics and evolution in R language. Bioinformatics 20:289-290. https://doi. org/10.1093/bioinformatics/btg412

Pinheiro J, Bates D et al. (2017) nlme: linear and nonlinear mixed effects models. R package version 3.1-131. https://CRAN.Rproject.org/package $=$ nlme

R Core Team (2017) R: a language and environment for statistical computing. R Foundation for Statistical Computing, Vienna

Sakurai A, Takahashi K (2016) Flowering phenology and reproduction of the Solidago virgaurea L. complex along an elevational gradient on Mt Norikura, central Japan. Plant Species Biol 32:270-278. https://doi.org/10.1111/1442-1984.12153

Scheepens JF, Stöcklin J (2013) Flowering phenology and reproductive fitness along a mountain slope: maladaptive responses to transplantation to a warmer climate in Campanula thyrsoides. Oecologia 171:679-691. https://doi.org/10.1007/s00442-012-2582-7

Scheepens JF, Frei ES et al (2010) Genotypic and environmental variation in specific leaf area in a widespread Alpine plant after transplantation to different altitudes. Oecologia 164:141-150. https://doi.org/10.1007/s00442-010-1650-0

Slavík B (2004) Solidago L.-zlatobýl. In: Slavík B, Štěpánkowá J (eds) Květena České Republiky 7. Academia, Praha, pp 114-123

Št' astná P, Klimešowá J et al (2012) Altitudinal changes in the growth and allometry of Rumex alpinus. Alp Botany 122:35-44. https:// doi.org/10.1007/s00035-012-0099-7

Stöcklin J, Armbruster GFJ (2016) Environmental filtering, not local adaptation of established plants, determines the occurrence of seed- and bulbil-producing Poa alpina in a local flora. Basic Appl Ecol 17:586-595. https://doi.org/10.1016/j.baae.2016.06.004

Stöcklin J, Kuss P et al (2009) Genetic diversity, phenotypic variation and local adaptation in the alpine landscape: case studies with alpine plant species. Bot Helv 119:125-133. https://doi. org/10.1007/s00035-009-0065-1

Takahashi K, Matsuki S (2016) Morphological variations of the Solidago virgaurea $\mathrm{L}$. complex along an elevational gradient on $\mathrm{Mt}$ Norikura, central Japan. Plant Species Biol 32:238-246. https:// doi.org/10.1111/1442-1984.12148

Takahashi K, Yoshida S (2009) How the scrub height of dwarf pine Pinus pumila decreases at the treeline. Ecol Res 24:847-854. https://doi.org/10.1007/s11284-008-0558-1

Theurillat J-P, Guisan A (2001) Potential impact of climate change on vegetation in the European Alps: a review. Clim Change 50:77109. https://doi.org/10.1023/A:1010632015572

Totland Ø (2001) Environment-dependent pollen limitation and selection on floral traits in an alpine species. Ecology 82:2233-2244. https://doi.org/10.1890/0012-9658(2001)082[2233:EDPLAS]2. $0 . \mathrm{CO} ; 2$

Totland $\varnothing$ (2004) No evidence for a role of pollinator discrimination in causing selection on flower size through female reproduction. Oikos 106:558-564. https://doi. org/10.1111/j.0030-1299.2004.12991.x

Trunschke J, Stöcklin J (2017) Plasticity of flower longevity in alpine plants is increased in populations from high elevation compared to low elevation population. Alp Bot 127:41-51. https://doi. org/10.1007/s00035-016-0176-4

Vaupel A, Matthies D (2012) Abundance, reproduction, and seed predation of an alpine plant decrease from the center towards the range limit. Ecology 93:2253-2262. https://doi.org/10.1890/11-2026.1

von Arx G, Edwards PJ et al (2006) Evidence for life history changes in high-altitude populations of three perennial forbs. Ecology 87:665-674. https://doi.org/10.1890/05-1041

Wagenitz G (1979) Compositae I: Allgemeine Teil, EupatoriumAchillea. In: Conert HJ, Hamann W, Schultze-Motel W, Wagenitz G (eds) Hegi Illustierte Flora von Mitteleuropa, vol 4.3. Parey Bucherverlag, Berlin, pp 16-32

Weppler T, Stöcklin J (2005) Variation of sexual and clonal reproduction in the alpine Geum reptans in contrasting altitudes and successional stages. Basic Appl Ecol 6:305-316. https://doi. org/10.1016/j.baae.2005.03.002

Wirth LR, Graf R et al (2010) Between-year variation in seed weights across altitudes in the high-alpine plant Eritrichum nanum. Plant Ecol 207:227-231. https://doi.org/10.1007/s11258-009-9667-3

Zhao Z-G, Wang Y-K (2015) Selection by pollinators on floral traits in generalized Trollius ranunculoides (Ranunculaceae) along altitudinal gradients. PLoS One 10(2):e0118299. https://doi. org/10.1371/journal.pone.0118299

Zuur AF, Ieno EN et al (2009) Mixed effects models and extensions in ecology with R. Springer, New York. https://doi. org/10.1007/978-0-387-87458-6 